\title{
BACK TO THE FUTURE, THE LEARNER STRIKES BACK: FEEDBACK AND REFLECTION AS KEY ELEMENTS IN MOOC RE-DESIGN
}

\author{
Conchúr Mac Lochlainn, Mairéad Nic Giolla Mhichíl, Elaine Beirne, Mark Brown, Dublin City \\ University, Ireland
}

\begin{abstract}
A general trend within research into Massive Open Online Courses (MOOCs) has been the study of learner behaviour and motivations using large-scale, quantitative studies to measure, correlate and predict forms of interaction and participation. Far few studies have focused on contextual, local and qualitative forms of inquiry, despite the great potential of such methods. In this paper, we discuss a preliminary study making use of qualitative data generated on an Irish language MOOC, namely learner comments on reflective steps each week. This data was analysed using an interpretive framework for elucidating both positive and negative forms of learner feedback. Three major themes are defined, relating to opinions regarding course materials, positive attitudes towards interaction and a broad metacognitive awareness of the process of learning. Implications for the design process and the importance of using such methods are briefly discussed.
\end{abstract}

\section{Introduction}

What motivates learners to study in MOOCs is a question that has been contemplated by researchers ever since MOOCs became part of the global learning ecology (e.g. Kizilcec \& Schneider, 2015). Primarily, this interest stems from the perceived close relationship between completion and participation, with a positive correlation usually theorised between these concepts. We view participation, as a complex and nuanced concept with many competing contextual and influencing factors. Researching such factors requires careful methodological consideration. The majority of MOOC-based research in this area adopts a distinctive quantitative approach when considering participation (e.g. Wang \& Baker, 2015; Jordan, 2015). While studies in related fields such as computer assisted language learning and distance learning have considered qualitative perspectives (see Murphy, 2011; Hurd, 2008), they are not as common among MOOC-centred studies. To address this gap in the empirical literature, this brief paper employs a qualitative, interpretive approach to analysing the motivations of MOOC learners over the length of a course at weekly intervals. The paper draws on Anderson's (2003) framework of learner interaction in online learning as a conceptual tool to consider participation. Data is primarily derived from a corpus of learner comments collected from the three week, Irish-language and culture MOOC, Irish 101, which is delivered through the FutureLearn platform. This is coupled with data derived from selfreported course survey instruments. The paper critically-reflects on the importance of such 
methodological and conceptual innovation and the importance of listening to "the learner voice" (Conole, 2008; p.126). The process by which that voice influenced learner design and redesign is also explored. The findings illustrate that participants' reasons for engagement suggest a form of integrated, self-regulated learning (Zimmerman \& Schunk, 1989), at least amongst those who comment. The study also highlights the impact of language learning nuances on learner participation as well as the impact of broader contextual dimensions beyond subject area.

\section{Background and Literature on MOOC learner motivations and continuation}

Understanding the motivations of those who participate in a MOOC is akin to opening a proverbial black-box. While several large meta-analyses exist on learner participation, they have primarily been concerned with uncovering trends and focuses. Studies such as Kizilcec, Piech, and Schneider (2013) and Ferguson and Clow (2015) take a macro-level approach to parsing behavioural patterns and suggest that taxonomies or clusters of learner engagement patterns exist. Research in the vein of Clow (2013) uses metaphors such as the funnel of participation to explain learner participation and completion while Wang and Baker (2018) employ psychological variables such as learner grit or persistence. Others have focused on the traits and characteristics of learners who have completed their studies (Breslow et al., 2013). The underlying premise of this research is that of a variance-based understanding of participation (Mohr, 1982). Learner responses are typically aggregated and averaged. Such studies are increasingly-prevalent across all domains of educational research (Ferguson et al., 2016) and they have provided insights into typical patterns of learner behaviour whilst also providing a basis by which to compare modalities of learning. Their contribution to learner participation in MOOCs is relatively limited, however, when attempting to uncover contextual factors. The limitations and scope of such MOOC-based studies are identified by Veletsianos, Collier, and Schneider (2015; p.574), as they critique a general discourse which suggest that "teaching and learning can be fully analyzed, understood and designed for by examining clickstream data". Many of these studies focus on what can be readily measured i.e. behaviour or activity within a MOOC-platform, or Twitter-related feed, and such measurements only provide a partial view of the habits and indeed "lifeworld" of such learning, as embedded in personal, social and contextual relations (Veletsianos, Reich, \& Pasquini, 2016; p.6). A promising development marrying the best of both worlds in this regard may be to use an analytical framework such as Henderikx, Kreijns, and Kalz's (2018: 358-60). This focuses specifically on measuring learner goals in a localised, contextual sense by asking whether they achieved their particular expectations from a MOOC. Anderson's updated (2003) model of online interaction provides a nuanced understanding when considering the broader concept of learner participation. Though, pre-dating MOOCs, it delineates between interactions between (a) learner and content, (b) the learner and instructor, and (c) the learner and other learners. Regarding the first and third aspects, Ferguson and Clow's (2015: 8) study found a general link between posting comments and course completion, whilst Swinnerton, Hotchkiss, and Morris' (2017; p.61) study 
distinguishes between MOOC-commenters and non-commenters in discussion forums. Furthermore, commenting in MOOCs can be considered not only from the perspective of those learners who comment or those who do not. It can also be viewed from the perspective that the presence of comments represents an active and engaged learning space for all learners (Hart, 2012) which may help to reduce perceived or actual social isolation (Gasevic et al., 2014).

\section{Methodology}

1,081 comments, providing a corpus of 52,000 words, were posted by learners in three weekly "review of the week" discussions on the Irish 101 MOOC. The total comments posted in the Irish 101 MOOC were 25,000, across approximately 90 learning steps. 5 standard questions were asked each week in this review step e.g. "what did you find difficult about week X? What was easy?". A broadly interpretive (Merriam, 2002; pp.6-7) approach to data analysis was adopted, with a focus on contextualising the interaction within wider MOOC participation. Leximancer, a qualitative data analysis tool, was used to analyse and thematically group comments. This was then crosschecked by the researchers to ensure an accurate fit to the semantic meaning of the data. This approach was adopted to increase validity and consistency (Creswell \& Miller, 2000). Three key non-language specific themes emerged consistently: (a) Attitudes towards course design and content (b) Enjoyment of social interaction (c) Metacognitive awareness of learning. The following section briefly sets out the findings in these three areas.

\section{Findings}

\section{Theme 1 - Attitudes to course design}

Many of the comments grouped under the attitudes towards course design theme illustrated that the learners were both agentful and reflexive regarding their learning, in addition to being quite willing to comment on aspects of course structure and design. Frequently, within comments they benchmarked MOOC learning content with their own particular learning goals and expectations (which may vary greatly (Ho et al., 2014; p.6)) regarding learning resources and activities within the MOOC:

"I enjoyed the materials and that new words are connected with my favourite activities: listen and repeat. I also liked to learn words. Well-done materials!" (Learner A)

For some, materials were extremely beneficial and aligned with expectations whilst others formulated suggestions within comments, these changes were integrated where possible in the iterative refinement of the MOOCs learning design:

"I think my main feedback to the educators is the need for more downloadable material of the sound bites in the presentations so those of us who are absolute beginners can hear them and then practise." (Learner B) 
These attitudes provide a central insight regarding MOOC learners: as typically-educated, aware and active learners, any design or instructional experience is at least on some level a process of co-construction, and this aspect of the learner voice is deeply valuable in providing solid feedback relating to provision, design and dissemination.

\section{Theme 2 - Enjoyment of interaction}

The second theme, enjoyment of interaction, centred on the importance and role of the interaction of learners with their peers, instructors and with other learners within the MOOC, in keeping with Anderson's framework:

"I also want to thank everyone both teachers and learners in this course that made me feel like I was a member of a community of like-minded people." (Learner C)

This comment illustrates that building "a bounded group motivated by learning and creating the terms for such learning through socially shared interactions" (Oleksandra \& Dawson, 2016; p.208) is an important outcome of good learning design but may also impact sustained motivation. Learners engaged in interactions with each other by providing advice and feedback could also be viewed as a factor in the construction of this community.

A sub-theme related to the interactional challenges was associated with the disciplinary area of learning a language. In keeping with several motivational theories common to both language learning and wider educational psychology, such as the concept of mastery orientation (Ames \& Archer, 1988) or intrinsic motivation - accomplishment (Noels et al., 2000; p.61), the difficulty of the language was both potentially demotivating (if the learner believed it was too difficult for them to achieve gains in) and a potential intensifier of motivation, as the challenge appealed to many learners:

"Lenition is giving me brain freeze and I think my pronunciation would make most people cry - it does me - but I'm enjoying the challenges and also the community!" (Learner D)

"The language is a tricksy one - difficult to catch hold of but I don't mind because my main reason for being here is to find out. About the complexity, the history, the tangles and tales of a fascinating country and people. Loving it." (Learner E)

This desire for greater interaction and the great enthusiasm for the subject matter shows language learning as deeply social and interactive, and as acknowledged in the distance language-learning literature (Carrió-Pastor, 2018; p.205), speaks to a particular pedagogical challenge faced by disciplines where the acquisition of knowledge and skills both play central roles. 


\section{Theme 3 - Metacognitive awareness}

The final theme, metacognitive awareness, is perhaps the most relevant to learning motivation and learning in MOOCs, beyond the context of learning languages. Comments demonstrated awareness that learning takes time, while also sharing strategies for learning. A common trend was that many felt that more time was needed to complete the MOOC. Comments also alluded to the adoption of learning activities outside of the MOOC to aid progress:

"I have enjoyed it but need more time to study the pronunciation. I don't imagine I will learn to speak the language in this short time but it gives me an insight and widens my knowledge of all things Irish. The course is detailed and more challenging than others I have undertaken." (Learner $H$ )

"I'm thoroughly enjoying this course! And I'm finding myself taking it quite seriously as I spread flash cards and other helpful ways to learn around my house!" (Learner I)

This awareness may be a core feature in positive MOOC learning, and a source of sustained motivation. Indeed, this ability, to reflect, and to create strategies that may contribute to goal achievement, might be critical, in the ability to be "motivationally, meta-cognitively and behaviourally active participants in their own learning process" (Zimmerman \& Schunk, 1989; p.329). Empirical evidence supports the distinction between high and low self-regulated learners in terms of MOOC outcomes, with high self-regulation associated with continuation (Littlejohn et al., 2016; pp.42-44). Fostering this sense of self-regulation is not easy, but it may be critical to ensure the largest number of persons possible can benefit from their participation in a MOOC.

\section{Discussion and conclusion}

Two conclusions can be drawn from the reporting of this preliminary research. The first is that discussion comments, particularly at points geared at generating reflective feedback, provide researchers with a wealth and depth of contextual information, which is not easily accessed through survey instruments. A wide array of social, affective and metacognitive forms of feedback and self-regulation were present within the data, with variation both from week to week and from learner to learner. In keeping with Zheng et al. (2015; p.1891), we hold that this research may afford researchers the ability to provide a "vivid picture of learning patterns", and to see how learners construe their own progress as it unfolds organically. By adopting a reflexive, interpretative approach and methods, it may be possible to "make the massive humane" (Sokolik, 2014; p.20) and indeed to listen to the learner voice (Conole, 2008).

Our second conclusion relates to the provision of these steps themselves, namely that they are a highly useful aspect of MOOC course design. Evidenced in this paper but also our experiences as learning designers and instructors, is that these spaces are highly useful in 
enabling learners to provide feedback that can be very valuable in MOOC redesign. Several trends from this initial analysis, such as providing more audio support, video provision and opportunities for social practice, have directly affected the re-design of subsequent runs of the course. Others, such as the general consensus on the difficulty of the language, have led to a focus on providing additional time estimates for task completion, and to restructure material substantially. Given that behind every course is a collection of research, experience and agency, there is particular value in harnessing these design affordances and the learner generated reflective evidence-base to inform the design and redesign process.

\section{References}

Ames, C., \& Archer, J. (1988). Achievement goals in the classroom: students learning strategies and motivation processes. Journal of Educational Psychology, 80(3), 260-267.

Anderson, T. (2003). Getting the mix right: An updated and theoretical rationale for interaction. The International Review of Research in Open and Distributed Learning, 4(2).

Breslow, L., Pritchard, D., DeBoer, J., Stump, G., Ho, A., \& Seaton, D. (2013). Studying Learning in the Worldwide Classroom: Research into edX's first MOOC. Research and Practice in Assessment, 8.

Carrió-Pastor, M. (2018). Teaching language and teaching literature in virtual environments. Springer Press.

Clow, D. (2013). MOOCs and the funnel of participation. Proceedings of the Third Conference on Learning Analytics and Knowledge (LAK), 2013, 185-189.

Conole, G. (2008). Listening to the learner voice: The ever changing landscape of technology for language use. ReCALL, 20(22). 124-140.

Creswell, J., \& Miller, D. (2000). Determining Validity in Qualitative Inquiry. Theory into Practice, 39(3). 124-130.

Ferguson, R., \& Clow, D. (2015, March). Examining engagement: Analysing learner subpopulations in Massive Open Online Courses (MOOCS). Paper presented at the $5^{\text {th }}$ International Learning Analytics and Knowledge Conference, 16-20 March.

Ferguson, R., Brasher, A., Clow, D., Cooper, A., Hillaire, G., Mittelmeier, J., Rienties, B., Ullman, T., Vuorikari, R., \& Castano, J. (2016). Research evidence on the use of Learning Analytics: Implications for Education Policy. EUROPA Scientific and Technical Reports.

Gasevic, D., Kovanovic, V., Joksimovic, S., \& Siemens, S. (2014). Where is Research on Massive Open Online Courses Headed? A Data Analysis of the MOOC Research Initiative. The International Review of Research in Open and Distributed Learning, 15(5). 134-176.

Hart, C. (2012). Factors Associated with Student Persistence in an Online Program of Study: A Review of the Literature. Journal of Interactive Online Learning, 11(1). 19-42. 
Henderickx, M., Kreijn, K., \& Kalz, K. (2018). Refining success and dropout in Massive Open Online Courses. Distance Education, 38(3). 353-368.

Ho, A., Chung, I., Reich, J., Coleman, C., Whitehall, J., Northcutt, C., Williams, J., Hansen, J., Lopez, G., \& Petersen, R. (2015). HarvardX and MITx: Two years of open courses. HarvardX working paper.

Hurd, S. (2008). Affect and strategy use in independent language learning. In S. Hurd, \& T. Lewis (Eds.), Language Learning Strategies in Independent Settings. Second Language Acquisition (pp. 218-236.). Bristol, UK: Multilingual Matters.

Jordan, K. (2015). Massive Open Online Courses completion rates revisited: Assessment, length and attrition. The International Review of Research in Open and Distributed Learning, 16(3).

Kizilcec, R., Piech, C., \& Schneider, E. (2013). Deconstructing disengagement: analysing learner subpopulations in Massive Open Online Courses.

Kizilcec, R., \& Scheider, E. (2015). Motivation as a lens to understand online learners: towards data-driven design with the OLEI scale. Computer-Human Interaction, 22(2), Article 6. ACM Trans.

Littlejohn, A., Hood, N., Milligan, C., \& Mustain, P. (2016). Learning in MOOCs: Motivations and self-regulated learning and MOOCs. The Internet and Higher Education, 29, 40-48.

Merriam, S. (2002). Qualitative Research in Practice: Examples for Discussion and Practice. San Francisco, CA: Wiley and Sons.

Mohr, L. B. (1982). Explaining Organizational Behavior. San Francisco, CA: Jossey-Bass.

Murphy, L. (2011). Why am I doing this? Maintaining motivation in distance language learning. In G. Murray, G. Xuesong, \& T. Lamb (Eds.), Identity, Motivation and Autonomy in Language Learning (pp. 107-124).

Noels, K., Pelletier, L., Clément, R., \& Vallerand, R. (2000). Why are you learning a second language? Motivational orientations and self-determination theory. Language Learning, 50(1), 57-85.

Oleksandra, P., \& Dawson, S. (2016). Untangling MOOC Learner Networks. Proceedings of the Sixth International Conference on Learning Analytics and Knowledge, LAK '16, 208212.

Sokolik, M. (2014). What constitutes an effective language MOOC? In E. Martín-Monje, \& E. Bárcena (Eds.), Language MOOCs: Providing learning, transcending boundaries (pp. 1632). Berlin: DeGruyter

Swinnerton, B., Hotchkiss, S., \& Morris, N. (2017). Comments in MOOCs: Who is doing the talking and does it help? Journal of Computer Assisted Language Learning, 33(1). 55-64. 
Veletsianos, G., Collier, A., \& Schneider, E. (2015). Digging deeper into learners' experiences in MOOCs: Participation in social networks outside of MOOCs, notetaking and contexts surrounding content consumption. British Journal of Educational Technology, May 2015, 570-587.

Veletsianos, G., Reich, J., \& Pasquini, L. (2016). The life between big data log events: Learners' strategies to overcome challenges in MOOCs. AERA Open, 2(3). 1-10.

Wang, Y., \& Baker, R. (2015). Content or platform: Why do learners complete MOOCs? MERLOT Journal of Online Learning and Teaching, 11(1), 17-30.

Wang, Y., \& Baker, R. (2018). Grit and intention: why do learners complete MOOCs? International Review of Research in Open and Distributed Learning, 19(3). 20-42.

Zheng, S., Rosson, M., Shih, P., \& Carroll, J. (2015). Understanding Student Motivation, Behaviors, and Perceptions in MOOCs. Paper presented at the Motivation and Dynamics in the Open Classroom, CSCW 2015.

Zimmerman, B. J. \& Schunk, D. H. (Eds.). (1989). Self-Regulated Learning and Academic Achievement: Theory, Research and Practice. New York: Springer-Verlag.

\section{Acknowledgement}

This study was conducted as part of the "Fáilte ar Líne" project which is co-funded by the Irish Government, Department of Culture, Heritage, and the Gaeltacht, under the TwentyYear strategy for the Irish Language, with support from the National Lottery. 